\title{
A case of vesical leiomyoma and acute urinary obstruction
}

\author{
M. E. FOSTER \\ F.R.C.S. \\ R. W. M. REES \\ F.R.C.S.
}

Department of Urology, University Hospital of Wales, Heath Park, Cardiff

\begin{abstract}
Summary
A case of acute urinary retention due to a vesical leiomyoma is described. This is an unusual presentation and the treatment is discussed.
\end{abstract}

KEY WORDS: acute urinary retention, vesical leiomyoma.

\section{Introduction}

A case of acute urinary retention in a female, caused by a leiomyoma of the bladder is described. Endoscopic follow-up for 5 years confirms a benign course.

\section{Case report}

A 42-year-old housewife presented with acute urinary retention, and a 24-hr history of increasing difficulty in micturition. Physical examination revealed an enlarged bladder. Intravenous urogram showed normal upper tracts with a large filling defect at the base of the bladder (Fig. 1). Cystoscopy revealed a large tumour on the right side of the bladder neck from which $50 \mathrm{~g}$ was resected transurethrally. Histology revealed bundles of mature smooth muscle consistent with a leiomyoma. Following resection, voiding was normal. Cystoscopy was repeated at yearly intervals for 5 years, but no recurrence was noted.

\section{Discussion}

Acute urinary retention in the female is unusual. This case illustrates acute retention due to a benign mesothelial vesical tumour. Only one other case of leiomyoma of the bladder and urinary retention has been reported which followed a Marshall-Marchetti repair for stress incontinence (Katz and Waldbaum, 1975). Although leiomyoma is the most common of

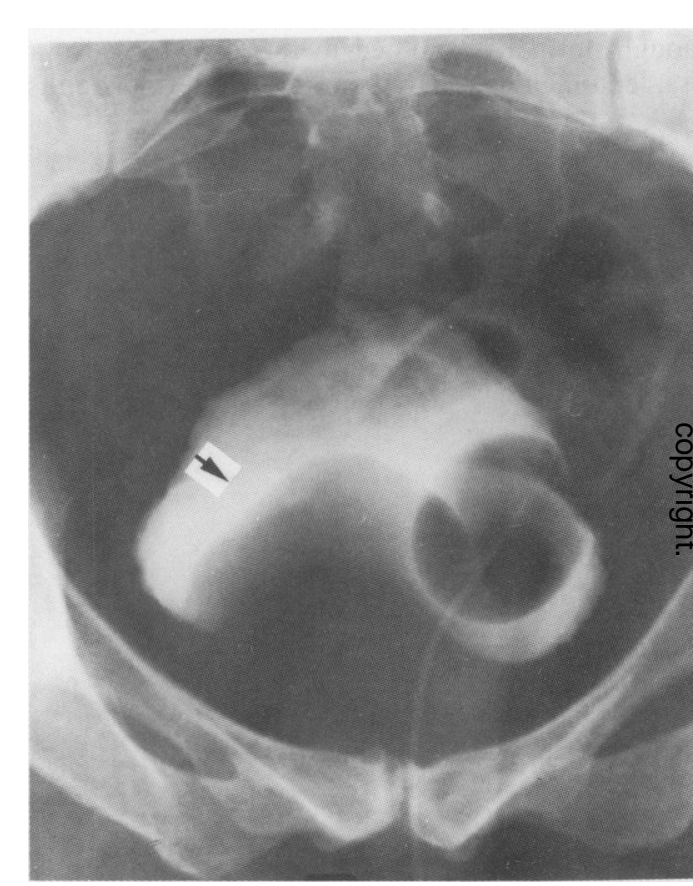

FIG. 1. Intravenous urogram appearance of leiomyoma.

the benign mesothelial vesical tumours, it is stili extremely rare. It is thought to derive from embry? onic rests. Campbell and Gislason (1953) describet one case and reviewed the literature. Since that time. there have only been isolated reports in the Englisto literature. The site of these tumours appears to be confined to the bladder neck and base. Theip resemblance to benign prostatic hypertrophy if behaviour has been noted (Thompson and Balfour 1974). This case demonstrates that acute urinare retention can be the presenting clinical feature of thi tumour. The long follow-up, with absence of recur: rence, confirms the benign nature of the tumour and suggests that transurethral resection is the treatmen of choice. 


\section{References}

Campbell, E.N. \& Gislason, F.J. (1953) Benign mesothelial tumours of the urinary bladder: a review of literature and a report of a case of leiomyoma. Journal of Urology, 70, 733.
KATZ, R.B. \& WALDBaum, R.S. (1975) Benign mesothelial tumour of bladder. Urology, 5, 236.

ThOMPSON, I.M. \& BALFOUR, J. (1974) Leiomyomatous vesical outlet obstruction. Urology, 3, 92.

(Accepted 6 September 1982) 